\title{
Photochemical Control of Protein Arginine Deiminase (PAD) Activity
}

Santanu Mondal ${ }^{1,2}$, Sangram S. Parelkar ${ }^{1,2}$, Mitesh $\operatorname{Nagar}^{1,2}$, Paul R. Thompson ${ }^{1,2^{*}}$

${ }^{1}$ Department of Biochemistry and Molecular Pharmacology, UMass Medical School, 364

Plantation Street, Worcester, MA 01605, USA

${ }^{2}$ Program in Chemical Biology, UMass Medical School, 364 Plantation Street, Worcester, MA, 01605, USA.

Running Title: Photochemical Control of PAD Activity

*Author to whom correspondence should be addressed: Department of Biochemistry and Molecular Pharmacology, University of Massachusetts Medical School, LRB 826, 364 Plantation Street, Worcester MA 01605 tel: 508-856-8492; fax: 508-856-6215; e-mail:

paul.thompson@umassmed.edu. 


\begin{abstract}
Protein Arginine deiminases (PADs) play an important role in the pathogenesis of various diseases, including rheumatoid arthritis, multiple sclerosis, lupus, ulcerative colitis and breast cancer. Therefore, the development of PAD-inhibitors has drawn significant research interest in recent years. Herein, we describe the development of the first photoswitchable PADinhibitors. These compounds possess an azobenzene photoswitch to optically control PAD activity. Screening of a series of inhibitors structurally similar to BB-Cl-Amidine afforded compounds $\mathbf{1}$ and $\mathbf{2}$ as the most promising candidates for the light-controlled inhibition of PAD2; the cis-isomer of $\mathbf{1}$ is 10 -fold more potent than its trans-isomer, whereas the transisomer of $\mathbf{2}$ is 45 -fold more potent than the corresponding cis-isomer. The altered inhibitory potency upon photoisomerization has been confirmed in a competitive activity-based protein profiling (ABPP) assay. Further investigations indicate that the trans-isomer of $\mathbf{2}$ is an irreversible inhibitor, whereas the cis-isomer acts as a competitive inhibitor. In cells, the trans-isomer of compound $\mathbf{1}$ is completely inactive, whereas the cis-isomer inhibits histone H3-citrullination in a dose-dependent manner. Taken together, $\mathbf{1}$ serves as the foundation for developing photopharmaceuticals that can be activated at the desired tissue, using light, to treat diseases where PAD activity is dysregulated.
\end{abstract}




\section{INTRODUCTION}

Protein arginine deiminases (PADs) are cysteine hydrolases that mediate the conversion of arginine to citrulline (Figure 1A). ${ }^{1,2}$ Five isozymes (PAD1, 2, 3, 4 and 6) are known but only four of them (PADs 1-4) are catalytically active. ${ }^{3}$ The deiminase activity of PADs 1-4 is strictly regulated by the presence of $\mathrm{Ca}^{2+}$ ions, and the holoenzymes are known to bind four (PAD1), five (PADs 3 and 4) and six (PAD2) calcium ions at distinct sites. ${ }^{4,5,6}$ Although calcium does not play a direct role in catalysis, recent crystal structures indicate that it induces a series of structural rearrangements that leads to the formation of the catalytically competent state. Particularly, the movement of the nucleophilic cysteine (Cys647 and Cys645 in PAD2 and PAD4, respectively) into the active site is triggered by calcium. ${ }^{6}$ PADmediated protein citrullination is known to regulate various cellular processes, including neutrophil extracellular trap (NET) formation, the epigenetic regulation of gene transcription, and the maintenance of pluripotency. Moreover, aberrant protein citrullination is associated with various autoimmune diseases, including rheumatoid arthritis (RA), lupus, multiple

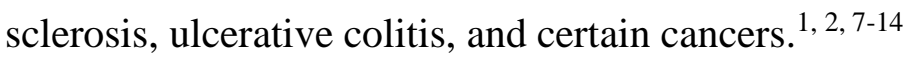

Given the potential role of PADs in human pathology, the development of PAD inhibitors has attracted significant attention. ${ }^{1,2,15}$ The most widely-used pan-PAD inhibitor is Cl-amidine (Figure 2B), which possesses a chloroacetamidine warhead that mimics the substrate guanidinium and irreversibly inhibits the PADs. Notably, Cl-amidine shows excellent efficacy in animal models of rheumatoid arthritis (RA), lupus, ulcerative colitis, spinal cord injury, breast cancer and atherosclerosis. ${ }^{13,16-18}$ Structure-activity relationships ultimately led to the development of BB-Cl-amidine, a second-generation PAD inhibitor in which the phenyl and carboxamide groups of Cl-Amidine are replaced with a biphenyl and benzimidazole group, respectively (Figure 1B). ${ }^{17} \mathrm{BB}-\mathrm{Cl}$-amidine exhibits at least 10-fold more potency than $\mathrm{Cl}$-amidine in cell-based and animal experiments. ${ }^{17,19,20}$ However, the 
fluoroacetamidine counterparts of $\mathrm{Cl}$-amidine and $\mathrm{BB}-\mathrm{Cl}$-amidine, i.e. F-Amidine and BB-Famidine, exhibit significantly less inhibitory activity, likely due to the lower electrophilicity of the fluoroacetamidine warhead (Figure 1B). ${ }^{21,22}$ In agreement with the proposed mechanism of inhibition, ${ }^{23}$ the cocrystal structure of PAD4 bound to BB-F-amidine indicates that nucleophilic attack of the active site cysteine on the haloacetamidine warhead displaces the halide and irreversibly modifies the enzyme active site (Figure 1C). ${ }^{15}$ Recently, we showed that BB-F-Yne, an alkyne bearing fluoroacetamidine based PAD inhibitor, is remarkably selective for the PADs in cell based assays. ${ }^{24}$ By contrast, BB-Cl-yne, possesses a number of off targets including, $\beta$-tubulin, $\beta$-Actin, clathrin heavy chain 1 (CLTC), bifunctional glutamate/proline-tRNA ligase (EPRS), heterogeneous nuclear ribonucleoprotein U (HNRPU). ${ }^{24}$ These observations suggest that localized activation or deactivation of chloroacetamidine-containing inhibitors in the target tissue may be an alternative approach to limit potential systemic toxicities.

Photopharmacology, which relies on the activation or inactivation of drug molecules in the targeted tissue by light, has led to the development of several light-controlled ionchannel blockers, receptor antagonists, antibiotics, and enzyme inhibitors. ${ }^{25-32}$ Light serves as a suitable external, noninvasive stimuli to modulate the potency of drug molecules and it can be delivered with high spatiotemporal precision and with a wide range of intensities as well as wavelengths. Photopharmaceuticals are generally developed by incorporating photoresponsive groups into bioactive molecules. The simplest and most widely-used example of such a photoresponsive element is an azobenzene. Azobenzenes undergo a transcis reversible isomerisation in the presence of light. While the thermodynamically more stable trans-isomer can be switched to the less stable, bent cis-isomer by UV light (i.e., 350 $\mathrm{nm})$, the reverse process can be achieved by shining blue light $(450 \mathrm{~nm}) .{ }^{29,} 30$ The excitation wavelengths and the half-life of the photoisomers can also be modulated by incorporating 
different substitutions on the azobenzene scaffold. The two isomers of azobenzene mainly differ from each other in shape and polarity and consequently, they exhibit different biological activities. Therefore, we hypothesized that the incorporation of azobenzene switches in BB-Cl-amidine, by replacing the biphenyl group, would result in a PAD-inhibitor that is structurally-similar to BB-Cl-amidine but can be activated or inactivated by light. Herein, we report the development of photoresponsive PAD inhibitors that can be used to optically control the inhibition of PADs in vitro and in cell-based assays. 


\section{RESULTS AND DISCUSSION}

To achieve the optical control of PAD-activity, we synthesized various azobenzenecontaining compounds carrying either a fluoro- or chloroacetamidine warhead (compounds 18, Scheme 1). While compounds $\mathbf{1}$ and $\mathbf{2}$ are the simple azobenzene-modified analogues of BB-Cl-Amidine and BB-F-Amidine, respectively, compounds 3-8 carries various substitutions on the azobenzene as well as the benzimidazole moiety. We hypothesized that the $p$-hydroxyl and $p$-dimethylamino substitutions on the terminal aromatic ring of the azobenzene moiety in compounds 3-6 may alter the binding affinity of different photoisomers for the enzyme active site by both electronic and steric influence. The N-methyl and 4methoxy substitutions on the benzimidazole ring in compounds $\mathbf{7}$ and $\mathbf{8}$ were incorporated because we previously showed that these modifications significantly increase the potency and isoform-specificity of benzimidazole-based PAD inhibitors. ${ }^{15}$ The synthesis of compounds 1-8 is depicted in Scheme 1 and it involves the common precursors 9 and 10, which were synthesized by following a previously reported procedure. ${ }^{15,17}$

With this family of the photoresponsive PAD-inhibitors in hand, we next investigated their trans-cis isomerisation by UV-visible spectroscopy (Figure 2A and Figure S1). The thermodynamically more stable trans-isomer of compound $\mathbf{1}(\mathbf{1 T})$ exhibits maximal absorption $\left(\lambda_{\max }\right)$ at $324 \mathrm{~nm}$ (Figure $\left.2 \mathrm{~B}\right)$. However, upon irradiation with UV-A $(\lambda=320-380$ $\mathrm{nm}$ ), this peak disappears with time, indicating the formation of the cis-isomer of this compound (i.e., 1C). A plot of absorbance at $324 \mathrm{~nm}$ versus time indicates that $40-60 \mathrm{~s}$ of UV-A exposure is sufficient to convert more than $80 \%$ of $\mathbf{1 T}$ into $\mathbf{1 C}$ (Figure 2C). A similar phenomenon was also observed for the fluoroacetamidine warhead-containing compound 2 (Figure 2D), indicating that the halogen substitution on the electrophilic warhead does not impact the photoisomerisation of compounds $\mathbf{1}$ and $\mathbf{2}$. We also investigated the thermal stability of the cis-isomer by UV-vis spectroscopy, as fast back conversion to the trans- 
isomer (from the thermodynamically less stable cis-isomer) would limit their utility. Both $\mathbf{1 C}$ and $2 \mathrm{C}$ exhibit remarkable stability in aqueous buffer at $37{ }^{\circ} \mathrm{C}$ as the change in absorbance at $324 \mathrm{~nm}$ over $12 \mathrm{~h}$ is negligible after irradiating $\mathbf{1 T}$ or $\mathbf{2 T}$ with UV-A lamps (Figure 2E and Figure S2). Both $\mathbf{1 C}$ and $\mathbf{2 C}$ can be switched back to their trans-form, i.e. $\mathbf{1 T}$ and $\mathbf{2 T}$, respectively, by irradiating with blue light $(\lambda=400-450 \mathrm{~nm}$ ) (Figure $\mathrm{S} 1 \mathrm{G}$ and $\mathrm{H}$ ) similarly to other azobenzene-containing photopharmaceuticals. ${ }^{25-32}$ This phenomenon, however, is not important for our purposes because compounds 1-8 are irreversible PAD-inhibitors and, as such, once the trans- or cis- isomer reacts with the active site cysteine, photoswitching will not turn off the inhibitor to regenerate the active enzyme. The photoswitching properties of compounds 3-8 were also characterised by UV-vis spectroscopy (Figure S1) and the observations are in agreement with the reported photoswitching behaviour of hydroxy- and diaminomethyl-substituted azobenzene photopharmaceuticals..$^{25-32}$

Having established the optimum photoswitching conditions (excitation wavelengths and exposure time), we set out to evaluate the inhibitory potency of the trans- (T) and cis- (C) isomers of the inhibitors in in vitro PAD-inhibition assays. PADs 1-4 were expressed and purified following standard protocols established in the Thompson lab. ${ }^{4,5}$ Inhibition of citrulline production was quantified using the COLDER assay (see experimental section). For PAD1, replacement of the biphenyl group in BB-Cl-amidine with the azobenzene decreases the potency of $\mathbf{1 T}$ by almost 8-fold, while the fluorinated analogue, 2T exhibits almost 6-fold higher activity than BB-F-amidine for this isozyme (Table 1). Interestingly, compound 3T, with a $p$-hydroxy substitution, exhibits almost 13 -fold higher activity than the unsubstituted analogue 1T, while the fluorinated analogue 4T exhibits 2-fold lower potency than 2T for PAD1. Furthermore, compounds 5T, 7T and 8T are inactive towards PAD1 (Table 1), indicating that the $p$-dimethylamino substitution on the azobenzene in combination with the $\mathrm{N}$-methyl and 4-methoxy substitutions on the benzimidazole ring disfavors binding of the 
inhibitor to the PAD1 active site. Next, we evaluated the inhibitory potency of the cisisomers of 1-8. The changes in the potency upon photoisomerisation of compounds 1-8 were generally found to be within 1-2-fold, although compound 6T exhibits 5-fold higher activity than $6 \mathrm{C}$.

Next, we tested their ability to inhibit PAD3 and PAD4. The potencies of the chloroand fluoroacetamidine warhead-containing compounds 1-8 for PAD3-inhibition were generally found to be lower than BB-Cl-Amidine and BB-F-Amidine, respectively. Compound 3T exhibited the highest potency in the series towards PAD3 (Table 1). However, upon photoswitching to the cis-isomer (3C), there was no change in potency. For other compounds in the series, photoisomerisation had modest (1.5-2-fold) effects on potency. For PAD4, compounds $\mathbf{1 T}$ and $\mathbf{2 T}$ exhibit similar potency to BB-Cl-amidine and BB-F-amidine (Table 1). As observed for PAD1 and PAD3, compound 3T exhibited the highest inhibitory activity towards PAD4, which is almost 2-fold higher than that of $\mathbf{1 T}$. However, its fluorinated analogue, $\mathbf{4 T}$, is only just as potent as compound $\mathbf{2 T}$ for PAD4 inhibition. While 5T (with a $p$-dimethylamino substitution) exhibits reasonable activity towards PAD4, the fluorinated analogue 6T is 5-fold less active (Table 1). It should be noted that 5T is completely selective to PAD4 over PAD1 and PAD3, and such selectivity over PAD1 is rare in the literature. However, compounds $\mathbf{7 T}$ and $\mathbf{8 T}$ exhibit poor inhibitory activity for PAD4, indicating that the benzimidazole-ring substitutions disfavor binding of the inhibitor to the active site of PAD4. Similar to the inhibition of PAD1 and 3, the cisconformation of these compounds are equipotent to the trans-conformation, e.g. $2 \mathrm{C}\left(k_{\text {inact }} / K_{\mathrm{I}}\right.$ $\left.=4150 \pm 420 \mathrm{M}^{-1} \mathrm{~min}^{-1}\right)$ inhibits PAD4 as well as $\mathbf{2 T}\left(k_{\text {inact }} / K_{\mathrm{I}}=3900 \pm 1300 \mathrm{M}^{-1} \mathrm{~min}^{-1}\right)$. Moreover, there was only a two-fold change in potency between compounds $\mathbf{1 T}$ and $\mathbf{1 C}$ (Table 1). 
Finally, we investigated the ability of these compounds to inhibit PAD2.

Dysregulated PAD2 activity is strongly associated with multiple sclerosis, RA and breast cancer. ${ }^{1,2}$ PAD2 is known to be secreted in the synovial fluid of arthritic joints, where it citrullinates numerous extracellular proteins, leading to the development of anticitrullinated protein antibodies (APCA), a diagnostic marker of RA. ${ }^{3,12}$ PAD2 is also responsible for the citrullination of histone $\mathrm{H} 3$ at R26 position, which triggers the localized decondensation of chromatin and activates gene transcription. ${ }^{13,33}$ Notably compound $\mathbf{1 T}$ is $\sim 10$-times less active than BB-Cl-amidine, indicating that replacement of the biphenyl group with the azobenzene disfavors interactions between the trans-form of the inhibitor and PAD2. Gratifyingly, its potency increases by 10-fold upon excitation to the cis-isomer, 1C (Table 1). Moreover, the $k_{\text {inact }} / K_{\mathrm{I}}$ value of $\mathbf{1 C}\left(6000 \pm 680 \mathrm{M}^{-1} \mathrm{~min}^{-1}\right)$ is almost identical to that of BBCl-amidine $\left(5000 \mathrm{M}^{-1} \mathrm{~min}^{-1}\right)$. The increased potency upon photoisomerisation is most likely due to enhanced binding to the PAD2 active site because the plots of $k_{\mathrm{obs}}$ versus inhibitor concentration move from linear (1T) to hyperbolic (1C) (Figure 3A), indicative of a lower $K_{\mathrm{I}}$ value for the $c$ is-isomer. The $k_{\text {inact }}$ and $K_{\mathrm{I}}$ values for $\mathbf{1 C}$ are $0.15 \mathrm{~min}^{-1}$ and $25.2 \mu \mathrm{M}$, respectively (Figure 3B). These results indicate that the less potent compound $\mathbf{1 T}$ can be activated to the more potent compound $\mathbf{1 C}$ for the inhibition of PAD2 in the presence of UVA radiation. Surprisingly, 2T, the fluorinated analogue of $\mathbf{1 T}$, is almost 45 -fold more active than its cis-isomer 2C (Table 1 and Figure 3C), indicating that the nature and size of the halogen atom in the haloacetamidine warhead plays an important role in the binding and reactivity of the inhibitor. 2T shows saturation kinetics with $k_{\text {inact }}$ and $K_{\mathrm{I}}$ values of $0.3 \mathrm{~min}^{-1}$ and $66.4 \mu \mathrm{M}$, respectively (Figure S4C). By contrast, 2C showed very little, if any, enzyme inactivation, as such a single $k_{\mathrm{obs}}$ was used to estimate the $k_{\text {inact }} / K_{\mathrm{I}}$ of $\mathbf{2 C}\left(k_{\text {inact }} / K_{\mathrm{I}} \leq 100 \pm 20\right.$ $\mathrm{M}^{-1} \min ^{-1}$ ) (Figure S4D). In comparison to compounds $\mathbf{1}$ and $\mathbf{2}$, compounds $\mathbf{3 C}$ and $\mathbf{4 C}$ are 4- and 5-fold, respectively, more active than 3T and 4T, indicating that the $p$-hydroxy 
substitution in the azobenzene ring suppresses the optical control of the inhibition of PAD2 activity (Table 1 and Figure 3C). Compound 6T is also $\sim 2$-times more potent than $6 \mathrm{C}$. Interestingly, 6C is 57-, 20- and 23-fold more selective for PAD2 than PAD1, PAD3 and PAD4, respectively. Such isozyme selectivity has rarely been observed amongst previously developed PAD inhibitors. Furthermore, compound $\mathbf{8 T}$ is $\sim 5$-times more active than $\mathbf{8 C}$, although the potency of $\mathbf{8 T}$ is very low (Table 1 and Figure 3C). Taken together, compounds $\mathbf{1}$ and $\mathbf{2}$ are the most promising candidates in the series for the optical control of PAD2 activity - compound 1 can be photo-activated by 10-fold, whereas compound $\mathbf{2}$ can be photodeactivated by 45 -fold.

To further confirm the results of our in vitro inhibition assays, we used a previously established competitive activity-based protein profiling (ABPP) assay to visualise the change in inhibitory potency upon photoisomerisation (Figure 4A and B). For these studies, PAD2 was treated with inhibitors in microplates for 30 min prior to the addition of rhodamineconjugated fluoroamidine (RFA), a PAD-targeted ABPP. For strong inhibitors, RFAlabelling will be blocked, whereas for weak inhibitor a smaller proportion of PAD2 would be occupied, and RFA-labelling is enhanced (Figure 4B).

Consistent, with the $k_{\text {inact }} / K_{\text {I }}$ data, $\mathbf{1 T}$ is a very weak PAD2 inhibitor (Figure 4C); the $\mathrm{IC}_{50}$ is $>100 \mu \mathrm{M}$. By contrast, the $\mathrm{IC}_{50}$ of $\mathbf{1 C}, 9.1 \mu \mathrm{M}$, is more than 10 -fold lower than that of 1T. Despite the fact that $\mathbf{2 T}$ is 45 -fold more potent than $\mathbf{2 C}$, these two isomers yielded similar $\mathrm{IC}_{50}$ values, i.e. $11.8 \mu \mathrm{M}$ and $23.8 \mu \mathrm{M}$ respectively, suggesting that $\mathbf{2 T}$ is only 2-times more active than 2C (Figure 4D). To reconcile this contradiction, we considered the possibility that $\mathbf{2 C}$ binds to the PAD2 active site in such a conformation that precludes its reaction with C647, the active site cysteine, but still inhibits the enzyme reversibly. To test this possibility, we determined the $K_{\mathrm{m}}$ of $\mathrm{N}_{\alpha}$-benzoyl-L-arginine ethyl ester (BAEE), a known substrate of PAD2, in the presence of increasing concentrations of $\mathbf{2 C}$. The resulting 
inhibition patterns indicate that $\mathbf{2 C}$ is a reversible, competitive inhibitor, with a $K_{\mathrm{i}}$ value of 25.2 $\mu \mathrm{M}$ (Figure S7). Since $\mathbf{3 C}$ is almost 4-fold more potent than $\mathbf{3 T}$ (Table 1), we also assayed this compound in this competitive ABPP assay. Interestingly, the $\mathrm{IC}_{50}$ of $\mathbf{3 C}$ is $>8$ fold lower than that of $\mathbf{3 T}$, roughly in agreement with the results obtained using the COLDER assay.

Motivated by these promising inhibition data, we next evaluated their ability to inhibit histone $\mathrm{H} 3$ citrullination in cells; histone $\mathrm{H} 3$ is citrullinated at multiple positions, including R2, R8, R17 and R26 by PAD2. ${ }^{33-35}$ For these experiments, HEK293T/PAD2 overexpressing cells ${ }^{36,37}$ were incubated with the inhibitor, $\mathrm{CaCl}_{2}$ and ionomycin (a calcium ionophore) for 3 $\mathrm{h}$, and then the cells were lysed, the soluble proteins in the lysate resolved by SDS-PAGE, and transferred to a PVDF membrane. The membrane was then incubated with primary antibodies for histone $\mathrm{H} 3$ and citrullinated histone $\mathrm{H} 3$ (Cit 2, 8, 17), followed by incubation with appropriate secondary antibodies and imaged by Licor analysis. Consistent with our in vitro data, 1T does not inhibit histone $\mathrm{H} 3$ citrullination even at $100 \mu \mathrm{M}$. By contrast, the light-activated isomer $\mathbf{1 C}$ inhibits citrullination in a dose-dependent manner (Figure 5), suggesting that compound $\mathbf{1}$ can be photoactivated to inhibit histone H3-citrullination in HEK293T/PAD2 cells. By contrast, 2T only showed modest inhibition ( $33 \%$ at $100 \mu \mathrm{M})$ and 2C did not show any activity (Figure S8A). Similarly, 3C was slightly more active than 3T in inhibiting H3 citrullination by PAD2 (Figure S8B). These results suggest that in addition to inhibitory potency, cell-permeability of the different isomers plays an important role in inhibiting PAD2 activity in the HEK293T/PAD2 cells.

We also evaluated the cytotoxicity of the photoisomers of compounds 1-3 and BB-Clamidine in the HEK293T/PAD2 cells. Compound 1, which exhibited the best results for the photoactivation of inhibition of PAD2 was as cytotoxic as BB-Cl-amidine (Figure S9). Notably, the trans- and cis isomers of $\mathbf{1}$ do not show any difference in the cytotoxicity, 
suggesting that the cytotoxicity of compound $\mathbf{1}$ does not originate from the inhibition of PAD2. By contrast, compounds $\mathbf{2}$ and $\mathbf{3}$ are less toxic than $\mathbf{1}$.

\section{Conclusions}

Herein, we report the development of the first photoswitchable PAD inhibitor. A series of compounds, 1-8, carrying an electrophilic warhead were evaluated and in vitro inhibition experiments indicate that these compounds can optically control PAD2 activity, with $\mathbf{1}$ and $\mathbf{2}$ being the most promising candidates. While the cis-isomer (1C) exhibits 10-fold higher potency than the trans-isomer (1T) of $\mathbf{1}$, the trans-isomer $(\mathbf{2 T})$ exhibits 45 -fold more potency than the cis-isomer (2C) of $\mathbf{2}$. Furthermore, alterations in the inhibitory potency upon photoisomerisation were confirmed using a competitive ABPP assay. This study indicates that the $\mathrm{IC}_{50}$ of $\mathbf{1 C}$ is $>10$-fold lower than that of $\mathbf{1 T}$. In contrast to the $k_{\text {inact }} / K_{\mathrm{I}}$ data, compound $\mathbf{2 C}$ is only 2-fold less potent than $\mathbf{2 T}$ in the ABPP-based assay. Detailed enzyme kinetics in the presence of increasing concentrations of $\mathbf{2 C}$ revealed that $2 \mathrm{C}$ is a reversible, competitive inhibitor of PAD2. Cell-based studies reveal that 1T is inactive, whereas the light-activated isomer $\mathbf{1 C}$ inhibits histone $\mathrm{H} 3$ citrullination in a dose-dependent manner in HEK293T/PAD2 cells.

In total, the present data sets a foundation for developing photopharmaceuticals to optically control PAD activity. Nevertheless, further research is required to overcome the limitations of the current molecules, including the poor tissue penetration of $350 \mathrm{~nm}$ light and modest isozyme selectivity. With regard to the former, introduction of fluoro- or chloro substitutions into the azobenzene scaffold will shift the excitation wavelength from UV to green or red light, respectively. ${ }^{38}$ With regard to the latter, the PADs generally show tissue or disease specific expression patterns. ${ }^{3}$ For example, PAD2 is overexpressed in luminal breast cancer cells and its expression correlates with the level of the HER2 protooncogene. ${ }^{13}, 33$ 
Thus, compound 1 represents a promising starting point for the development of photopharmaceuticals against diseases in which PAD2 activity is dysregulated. Nevertheless, improvements in potency and interisozyme selectivity will likely be necessary and could be achieved by modifying the chromophore. 


\section{EXPERIMENTAL SECTION}

Materials and methods. Fmoc-Orn(Boc)-OH was purchased from Chem-Impex

International, Inc. 4-(phenylazo)benzoyl chloride, p-(p-dimethylaminophenylazo)benzoate dehydrate, DIPEA, anhydrous methanol, DMF, dichloromethane, piperidine, triethylamine, trifluoroacetic acid, chloroacetonitrile, fluoroacetonitrile and HPLC-grade acetonitrile were obtained from Sigma-Aldrich. 4'-Hydroxyazobenzene-4-carboxylic acid was bought from TCI Chemicals. Precoated silica gel plates were purchased from Merck. Deuterated solvents were acquired from Cambridge Isotope Laboratories. Mouse monoclonal anti-histone H3 (catalogue no. ab10799) and rabbit polyclonal anti-H3 (Citrulline R2, R8 and R17) (catalogue no. ab5103) were purchased from Abcam. NMR spectra were recorded in $d_{4}-\mathrm{MeOH}$ or $d_{6-}$ DMSO as solvent. ${ }^{1} \mathrm{H}$ and ${ }^{13} \mathrm{C}$ NMR spectra were recorded using a Bruker $500 \mathrm{MHz}$ NMR spectrometer. Chemical shift values are cited with respect to $\mathrm{SiMe}_{4}$ as the internal standard. Column chromatography was carried out in glass columns. Final compounds were purified by reverse-phase HPLC using a semi-preparative C18 column (Agilent, $21.2 \times 250 \mathrm{~mm}, 10$ $\mu \mathrm{m})$ and water/acetonitrile gradient supplemented with $0.05 \%$ trifluoroacetic acid.

Synthesis. Detailed procedures for the synthesis of compounds 1-8 are given in the supporting information. All the compounds were isolated as trifluoroacetate salts and were characterized using ${ }^{1} \mathrm{H},{ }^{13} \mathrm{C}$ NMR spectroscopy and ESI-Mass spectrometry. The purity of the compounds was analyzed by analytical HPLC.

Inactivation kinetics. Inactivation kinetic parameters for compounds 1-8 were determined by following reported procedures. ${ }^{22,} 23$ Briefly, PAD1, PAD2, PAD4 $(2 \mu \mathrm{M})$ or PAD3 (5 $\mu \mathrm{M})$ was added to a prewarmed $\left(10 \mathrm{~min}, 37^{\circ} \mathrm{C}\right)$ inactivation mixture $(100 \mathrm{mM}$ TRIS pH 7.4, $50 \mathrm{mM} \mathrm{NaCl}, 10 \mathrm{mM} \mathrm{CaCl} 2,2 \mathrm{mM}$ DTT, with a final volume of $50 \mu \mathrm{L}$ ) containing various concentrations of inhibitors. Aliquots $(6 \mu \mathrm{L})$ of the inactivation mixture were removed at 
various time points and were added to a prewarmed $\left(10 \mathrm{~min}, 37{ }^{\circ} \mathrm{C}\right)$ reaction mixture $(100$ mM TRIS pH 7.4, $50 \mathrm{mM} \mathrm{NaCl}, 10 \mathrm{mM} \mathrm{CaCl}_{2}, 2 \mathrm{mM}$ DTT, and $10 \mathrm{mM}$ BAEE or $10 \mathrm{mM}$ BAA for PAD3, with a final volume of $60 \mu \mathrm{L}$ ). The reactions were quenched with liquid nitrogen after 15 min and citrulline production was quantified using the COLDER assay. 5, 39 The time-dependence of PAD inhibition was fit to equation 1,

$$
v=v_{0} \mathrm{e}^{-k t}
$$

using Grafit, version 5.0.11, where $v$ is velocity, $v_{0}$ is initial velocity, $k$ (or $k_{\mathrm{obs}}$ is the pseudofirst-order rate constant of inactivation, and $t$ is the time. If the rates of inactivation reached saturation, the concentration dependence of $k_{\mathrm{obs}}$ was fit to equation 2 ,

$$
k_{\text {obs }}=k_{\text {inact }}[\mathrm{I}] /\left(K_{\mathrm{I}}+[\mathrm{I}]\right)
$$

using Grafit, version 5.0.11, where $k_{\text {inact }}$ is the maximal rate of inactivation, $K_{\mathrm{I}}$ is the concentration of inhibitor that yields half-maximal inactivation, and $[\mathrm{I}]$ is the concentration of inhibitor. If the plot of $k_{\mathrm{obs}}$ versus [I] did not saturate and was linear, then the value of $k_{\text {inact }} / K_{\text {I }}$ was determined from the slope of the line. All the experiments were carried out at least in duplicate.

RFA-labelling. The labeling of PAD2 with RFA in the presence of inhibitor was carried out by following a previously reported procedure. ${ }^{36,40,41}$ Briefly, PAD2 ( $2 \mu \mathrm{M}$ final) was added to the reaction mixture (100 $\mathrm{mM}$ TRIS $\mathrm{pH} 7.4,50 \mathrm{mM} \mathrm{NaCl}, 10 \mathrm{mM} \mathrm{CaCl}_{2}$, and $2 \mathrm{mM}$ DTT in a final volume of $20 \mu \mathrm{L}$ ) containing DMSO or various concentrations of the inhibitor. The mixture was incubated at $37{ }^{\circ} \mathrm{C}$ for $30 \mathrm{~min}$, followed by addition of RFA (10 $\mu \mathrm{L}, 2 \mu \mathrm{M}$ final). Then the reaction mixture was incubated at $37{ }^{\circ} \mathrm{C}$ for a further $2 \mathrm{~h}$, quenched with $5 \mathrm{X}$ SDSPAGE dye, incubated at $95{ }^{\circ} \mathrm{C}$ for $15 \mathrm{~min}$ and then loaded onto a $10 \%$ SDS-PAGE gel. After electrophoresis, fluorescence of the protein bands was recorded using a typhoon scanner (excitation/emission maxima of $\sim 546 / 579$, respectively). Fluorescence intensity of the 
protein bands was quantified using Image J software and was plotted against the concentration of the inhibitor to obtain the $\mathrm{IC}_{50}$ values.

Histone H3 Citrullination in HEK293TPAD2 Cells. HEK293T cells stably expressing human PAD2 (HEK293T/PAD2) were cultured as reported earlier. ${ }^{36,37}$ Cells were grown to $\sim 90 \%$ confluence, trypsinized, quenched with complete media and harvested by centrifugation at 3,000 rpm for $3.5 \mathrm{~min}$. Then the cells were washed with $1 \mathrm{X}$ HBS four times and were resuspended in $1 \mathrm{X}$ HBS at $8 \times 10^{6}$ cells $/ \mathrm{mL} .4 \times 10^{5}$ cells were used for subsequent assays with each inhibitor concentration. Calcium chloride $(1 \mathrm{mM})$, ionomycin $(10 \mu \mathrm{M})$, and either DMSO or various concentrations of inhibitor were incubated with the cells for $3 \mathrm{~h}$. The final concentration of DMSO in each sample was $1 \%$. Triton X-100 (1\% final) was then added to each sample and the suspension was sonicated at $4{ }^{\circ} \mathrm{C}$ for $1 \mathrm{~h}$, followed by centrifugation at $21,000 \mathrm{~g}$ for $15 \mathrm{~min}$. Lysates were collected, soluble proteins in the lysates were quantified using the DC-assay (Bio-Rad) and were normalized. $2 \mu \mathrm{g}$ of protein was loaded onto a 4-15\% gradient SDS-PAGE gel, separated by electrophoresis and proteins were then transferred to PVDF membrane (Bio-Rad) at $80 \mathrm{~V}$ for $50 \mathrm{~min}$. The membrane was then blocked by treating with phosphate buffered saline containing $0.1 \%$ Tween-20 (PBST) and 5\% BSA, and the blocked membrane was incubated with primary antibodies for histone $\mathrm{H} 3$ $(1: 1,000)$ and histone H3Cit 2,8,17 (1:1000) in PBST with 5\% BSA for $12 \mathrm{~h}$ at $4{ }^{0} \mathrm{C}$. After washing the membrane with PBST, it was incubated with anti-mouse and anti-rabbit IgG Licor conjugate (1:5000) in PBST and 5\% BSA for $1 \mathrm{~h}$ at $25{ }^{\circ} \mathrm{C}$. The membrane was then washed with PBST and imaged by Licor analysis.

Cytotoxicity Studies. HEK293T/PAD2 cells were plated $\left(2 \times 10^{4}\right.$ cells/well $)$ in a 96-well plate and were allowed to grow for $24 \mathrm{~h}$. DMSO or various concentrations of inhibitor were added to the wells and incubated for $24 \mathrm{~h}$. Cell viability was measured using the XTT reagent kit (ATCC) by recording the absorbance at $475 \mathrm{~nm}$ and $660 \mathrm{~nm}$. An eight-point 
dose-response curve was fit to the following equation 3 using GraphPad Prism 7.03 to determine the $\mathrm{EC}_{50}$ values for cell-growth inhibition,

$$
\mathrm{Y}=\text { Bottom }+(\text { Top-Bottom }) /\left[1+10^{((\operatorname{logEC} 50-\mathrm{X}) * \text { Hillslope })}\right]
$$

where Top and Bottom are plateaus of the dose-response curve, $\mathrm{X}$ is the log of inhibitorconcentration, Hillslope is the slope factor or Hill slope. 


\section{ASSOCIATED CONTENT}

Supporting information. Full synthetic procedures, NMR and ESI-MS characterization, PAD inactivation kinetics, RFA-labelling of PAD2, inhibition of histone $\mathrm{H} 3$ citrullination, cytotoxicity studies and Figures S1-S25. This information is available free of charge via the Internet at http://pubs.acs.org.

\section{AUTHOR INFORMATION}

Corresponding Author. *Tel.: (508)-856-8492. Fax: 508-856-6215. E-mail:

paul.thompson@umassmed.edu.

ORCID ID

Paul R. Thompson: 0000-0002-1621-3372

Santanu Mondal: 0000-0002-7399-8364

\section{ACKNOWLEDGEMENTS}

This work was supported in part by NIH grant R35GM118112 (P.R.T.). 


\section{ABBREVIATIONS}

RA, Rheumatoid arthritis; PAD, Protein arginine deiminase; ACPA, Anti-citrullinated protein antibodies; NET, Neutrophil extracellular trap; RFA, Rhodamine-conjugated F-amidine; ABPP, Activity-based protein profiling. 


\section{REFERENCES}

(1) Fuhrmann, J., Clancy, K. W., and Thompson, P. R. (2015) Chemical Biology of Protein Arginine Modifications in Epigenetic Regulation, Chem Rev 115, 5413-5461.

(2) Fuhrmann, J., and Thompson, P. R. (2016) Protein Arginine Methylation and Citrullination in Epigenetic Regulation, ACS Chem Bio 11, 654-668.

(3) Vossenaar, E. R., Zendman, A. J. W., van Venrooij, W. J., and Pruijn, G. J. M. (2003) PAD, a growing family of citrullinating enzymes: genes, features and involvement in disease, BioEssays 25, 1106-1118.

(4) Knuckley, B., Causey, C. P., Jones, J. E., Bhatia, M., Dreyton, C. J., Osborne, T. C., Takahara, H., and Thompson, P. R. (2010) Substrate Specificity and Kinetic Studies of PADs 1, 3, and 4 Identify Potent and Selective Inhibitors of Protein Arginine Deiminase 3, Biochemistry 49, 4852-4863.

(5) Kearney, P. L., Bhatia, M., Jones, N. G., Yuan, L., Glascock, M. C., Catchings, K. L., Yamada, M., and Thompson, P. R. (2005) Kinetic Characterization of Protein Arginine Deiminase 4: A Transcriptional Corepressor Implicated in the Onset and Progression of Rheumatoid Arthritis, Biochemistry 44, 10570-10582.

(6) Slade, D. J., Fang, P., Dreyton, C. J., Zhang, Y., Fuhrmann, J., Rempel, D., Bax, B. D., Coonrod, S. A., Lewis, H. D., Guo, M., Gross, M. L., and Thompson, P. R. (2015) Protein Arginine Deiminase 2 Binds Calcium in an Ordered Fashion: Implications for Inhibitor Design, ACS Chem Bio 10, 1043-1053.

(7) Li, P., Li, M., Lindberg, M. R., Kennett, M. J., Xiong, N., and Wang, Y. (2010) PAD4 is essential for antibacterial innate immunity mediated by neutrophil extracellular traps, J Exp Med 207, 1853-1862. 
(8) Slade, D. J., Subramanian, V., and Thompson, P. R. (2014) Citrullination unravels stem cells, Nat Chem Bio 10, 327.

(9) Christophorou, M. A., Castelo-Branco, G., Halley-Stott, R. P., Oliveira, C. S., Loos, R., Radzisheuskaya, A., Mowen, K. A., Bertone, P., Silva, J. C. R., Zernicka-Goetz, M., Nielsen, M. L., Gurdon, J. B., and Kouzarides, T. (2014) Citrullination regulates pluripotency and histone H1 binding to chromatin, Nature 507, 104.

(10) Jones, J., Causey, C., Knuckley, B., Slack-Noyes, J. L., and Thompson, P. R. (2009) Protein arginine deiminase 4 (PAD4): current understanding and future therapeutic potential, Curr Opin Drug Disc 12, 616-627.

(11) Moscarello, M. A., Pritzker, L., Mastronardi, F. G., and Wood, D. D. (2002) Peptidylarginine deiminase: a candidate factor in demyelinating disease, $J$ Neurochem 81, 335-343.

(12) Damgaard, D., Senolt, L., Nielsen, M. F., Pruijn, G. J., and Nielsen, C. H. (2014) Demonstration of extracellular peptidylarginine deiminase (PAD) activity in synovial fluid of patients with rheumatoid arthritis using a novel assay for citrullination of fibrinogen, Arthritis Res Ther 16, 498.

(13) McElwee, J. L., Mohanan, S., Griffith, O. L., Breuer, H. C., Anguish, L. J., Cherrington, B. D., Palmer, A. M., Howe, L. R., Subramanian, V., Causey, C. P., Thompson, P. R., Gray, J. W., and Coonrod, S. A. (2012) Identification of PADI2 as a potential breast cancer biomarker and therapeutic target, BMC Cancer 12, 500.

(14) Mohanan, S., Cherrington, B. D., Horibata, S., McElwee, J. L., Thompson, P. R., and Coonrod, S. A. (2012) Potential Role of Peptidylarginine Deiminase Enzymes and Protein Citrullination in Cancer Pathogenesis, Biochem Res Int 2012, 11. 
(15) Muth, A., Subramanian, V., Beaumont, E., Nagar, M., Kerry, P., McEwan, P., Srinath, H., Clancy, K., Parelkar, S., and Thompson, P. R. (2017) Development of a Selective Inhibitor of Protein Arginine Deiminase 2, J Med Chem 60, 3198-3211.

(16) Willis, V. C., Gizinski, A. M., Banda, N. K., Causey, C. P., Knuckley, B., Cordova, K. N., Luo, Y., Levitt, B., Glogowska, M., Chandra, P., Kulik, L., Robinson, W. H., Arend, W. P., Thompson, P. R., and Holers, V. M. (2011) N- $\alpha$-benzoyl-N5-(2-chloro1-iminoethyl)-1-ornithine amide, a Protein Arginine Deiminase Inhibitor, Reduces the Severity of Murine Collagen-Induced Arthritis, J Immunol 186, 4396-4404.

(17) Knight, J. S., Subramanian, V., O'Dell, A. A., Yalavarthi, S., Zhao, W., Smith, C. K., Hodgin, J. B., Thompson, P. R., and Kaplan, M. J. (2015) Peptidylarginine deiminase inhibition disrupts NET formation and protects against kidney, skin and vascular disease in lupus-prone MRL/lpr mice, Ann Rheum Dis 74, 2199-2206.

(18) Knight, J. S., Luo, W., O’Dell, A. A., Yalavarthi, S., Zhao, W., Subramanian, V., Guo, C., Grenn, R. C., Thompson, P. R., Eitzman, D. T., and Kaplan, M. J. (2014) Peptidylarginine Deiminase Inhibition Reduces Vascular Damage and Modulates Innate Immune Responses in Murine Models of Atherosclerosis, Circ Res 114, 947956.

(19) Ghari, F., Quirke, A.-M., Munro, S., Kawalkowska, J., Picaud, S., McGouran, J., Subramanian, V., Muth, A., Williams, R., Kessler, B., Thompson, P. R., Fillipakopoulos, P., Knapp, S., Venables, P. J., and La Thangue, N. B. (2016) Citrullination-acetylation interplay guides E2F-1 activity during the inflammatory response, Sci $A d v 2$. 
(20) Kawalkowska, J., Quirke, A.-M., Ghari, F., Davis, S., Subramanian, V., Thompson, P. R., Williams, R. O., Fischer, R., La Thangue, N. B., and Venables, P. J. (2016) Abrogation of collagen-induced arthritis by a peptidyl arginine deiminase inhibitor is associated with modulation of T cell-mediated immune responses, Sci Rep 6, 26430.

(21) Luo, Y., Knuckley, B., Lee, Y.-H., Stallcup, M. R., and Thompson, P. R. (2006) A Fluoroacetamidine-Based Inactivator of Protein Arginine Deiminase 4: Design, Synthesis, and in Vitro and in Vivo Evaluation, J Am Chem Soc 128, 1092-1093.

(22) Luo, Y., Arita, K., Bhatia, M., Knuckley, B., Lee, Y.-H., Stallcup, M. R., Sato, M., and Thompson, P. R. (2006) Inhibitors and Inactivators of Protein Arginine Deiminase 4: Functional and Structural Characterization, Biochemistry 45, 11727-11736.

(23) Knuckley, B., Causey, C. P., Pellechia, P. J., Cook, P. F., and Thompson, P. R. (2010) Haloacetamidine-based inactivators of Protein Arginine Deiminase 4 (PAD4): Evidence that General Acid Catalysis Promotes Efficient Inactivation, Chembiochem $11,161-165$.

(24) Nemmara, V. V., Subramanian, V., Muth, A., Mondal, S., Salinger, A. J., Maurais, A. J., Tilvawala, R., Weerapana, E., and Thompson, P. R. (2018) The Development of Benzimidazole-Based Clickable Probes for the Efficient Labeling of Cellular Protein Arginine Deiminases (PADs), ACS Chem Biol 10.1021/acschembio. 7 b00957.

(25) Broichhagen, J., Schönberger, M., Cork, S. C., Frank, J. A., Marchetti, P., Bugliani, M., Shapiro, A. M. J., Trapp, S., Rutter, G. A., Hodson, D. J., and Trauner, D. (2014) Optical control of insulin release using a photoswitchable sulfonylurea, Nat Comm 5, 5116. 
(26) Velema, W. A., van der Berg, J. P., Hansen, M. J., Szymanski, W., Driessen, A. J. M., and Feringa, B. L. (2013) Optical control of antibacterial activity, Nat Chem 5, 924.

(27) Reisinger, B., Kuzmanovic, N., Löffler, P., Merkl, R., König, B., and Sterner, R. (2014) Exploiting Protein Symmetry To Design Light-Controllable Enzyme Inhibitors, Angew Chem Int Edit 53, 595-598.

(28) Szymanski, W., Ourailidou, M. E., Velema, W. A., Dekker, F. J., and Feringa, B. L. (2015) Light-Controlled Histone Deacetylase (HDAC) Inhibitors: Towards Photopharmacological Chemotherapy, Chem Eur J 21, 16517-16524.

(29) Velema, W. A., Szymanski, W., and Feringa, B. L. (2014) Photopharmacology: Beyond Proof of Principle, J Am Chem Soc 136, 2178-2191.

(30) Broichhagen, J., Frank, J. A., and Trauner, D. (2015) A Roadmap to Success in Photopharmacology, Acc Chem Res 48, 1947-1960.

(31) Barber, D. M., Liu, S.-A., Gottschling, K., Sumser, M., Hollmann, M., and Trauner, D. (2017) Optical control of AMPA receptors using a photoswitchable quinoxaline-2,3dione antagonist, Chem Sci 8, 611-615.

(32) Broichhagen, J., Podewin, T., Meyer-Berg, H., von Ohlen, Y., Johnston, N. R., Jones, B. J., Bloom, S. R., Rutter, G. A., Hoffmann-Röder, A., Hodson, D. J., and Trauner, D. (2015) Optical Control of Insulin Secretion Using an Incretin Switch, Angew Chem Int Edit 54, 15565-15569.

(33) Zhang, X., Bolt, M., Guertin, M. J., Chen, W., Zhang, S., Cherrington, B. D., Slade, D. J., Dreyton, C. J., Subramanian, V., Bicker, K. L., Thompson, P. R., Mancini, M. A., Lis, J. T., and Coonrod, S. A. (2012) Peptidylarginine deiminase 2-catalyzed histone 
H3 arginine 26 citrullination facilitates estrogen receptor $\alpha$ target gene activation, Proc Natl Acad Sci USA 109, 13331-13336.

(34) Cuthbert, G. L., Daujat, S., Snowden, A. W., Erdjument-Bromage, H., Hagiwara, T., Yamada, M., Schneider, R., Gregory, P. D., Tempst, P., Bannister, A. J., and Kouzarides, T. (2004) Histone Deimination Antagonizes Arginine Methylation, Cell $118,545-553$.

(35) Clancy, K. W., Russell, A.-M., Subramanian, V., Nguyen, H., Qian, Y., Campbell, R. M., and Thompson, P. R. (2017) Citrullination/Methylation Crosstalk on Histone H3 Regulates ER-Target Gene Transcription, ACS Chem Bio 12, 1691-1702.

(36) Lewallen, D. M., Bicker, K. L., Madoux, F., Chase, P., Anguish, L., Coonrod, S., Hodder, P., and Thompson, P. R. (2014) A FluoPol-ABPP PAD2 High-Throughput Screen Identifies the First Calcium Site Inhibitor Targeting the PADs, ACS Chem Bio 9, 913-921.

(37) Lewallen, D. M., Bicker, K. L., Subramanian, V., Clancy, K. W., Slade, D. J., Martell, J., Dreyton, C. J., Sokolove, J., Weerapana, E., and Thompson, P. R. (2015) Chemical Proteomic Platform To Identify Citrullinated Proteins, ACS Chem Bio 10, 2520-2528.

(38) Wegener, M., Hansen, M. J., Driessen, A. J. M., Szymanski, W., and Feringa, B. L. (2017) Photocontrol of Antibacterial Activity: Shifting from UV to Red Light Activation, J Am Chem Soc 139, 17979-17986.

(39) Knipp, M., and Vašák, M. (2000) A Colorimetric 96-Well Microtiter Plate Assay for the Determination of Enzymatically Formed Citrulline, Anal Biochem 286, 257-264.

(40) Luo, Y., Knuckley, B., Bhatia, M., Pellechia, P. J., and Thompson, P. R. (2006) Activity-Based Protein Profiling Reagents for Protein Arginine Deiminase 4 (PAD4): 
Synthesis and in vitro Evaluation of a Fluorescently Labeled Probe, J Am Chem Soc $128,14468-14469$.

(41) Knuckley, B., Luo, Y., and Thompson, P. R. (2008) Profiling Protein Arginine Deiminase 4 (PAD4): A novel screen to identify PAD4 inhibitors, Bioorg Med Chem $16,739-745$. 
Table $1 . k_{\text {inact }} / K_{\text {I }}$ vales for the inhibition of PADs $1-4$ by BB-Cl-Amidine, BB-F-Amidine, and trans- (T) and cis- (C) isomers of compounds 1-8 (see Scheme 1 for variable groups).

\section{Compounds \&}

$k_{\text {inact }} / K_{\mathrm{I}}\left(\mathbf{M}^{-1} \mathrm{~min}^{-1}\right)$

photoisomers

PAD1

PAD2

PAD3

\section{PAD4}

\begin{tabular}{|c|c|c|c|c|c|}
\hline \multicolumn{2}{|c|}{ BB-Cl-Amidine } & $16000^{\mathrm{a}}$ & $5000^{\mathrm{a}}$ & $6000^{\mathrm{a}}$ & $14000^{\mathrm{a}}$ \\
\hline \multicolumn{2}{|c|}{ BB-F-Amidine } & $900^{\mathrm{a}}$ & $1200^{\mathrm{a}}$ & $3400^{\mathrm{a}}$ & $3750^{\mathrm{a}}$ \\
\hline \multirow{2}{*}{1} & $\mathbf{T}$ & $2300 \pm 200^{\mathrm{b}}$ & $600 \pm 30^{\mathrm{b}}$ & $1000 \pm 60^{b}$ & $10510 \pm 590^{\mathrm{c}}$ \\
\hline & $\mathbf{C}$ & $2000 \pm 100^{b}$ & $5970 \pm 670^{c}$ & $1500 \pm 40^{\mathrm{b}}$ & $4900 \pm 100^{b}$ \\
\hline \multirow{2}{*}{2} & $\mathbf{T}$ & $4920 \pm 760^{c}$ & $4520 \pm 760^{c}$ & $500 \pm 77^{b}$ & $3880 \pm 1320^{c}$ \\
\hline & $\mathbf{C}$ & $2850 \pm 320^{c}$ & $\leq 100 \pm 20^{\mathrm{de}}$ & $1100 \pm 40^{\mathrm{b}}$ & $4150 \pm 420^{c}$ \\
\hline \multirow{2}{*}{3} & $\mathbf{T}$ & $28770 \pm 7020^{c}$ & $2100 \pm 100^{\mathrm{b}}$ & $6500 \pm 100^{\mathrm{b}}$ & $19920 \pm 2170^{c}$ \\
\hline & $\mathbf{C}$ & $12000 \pm 570^{c}$ & $7330 \pm 1280^{c}$ & $6300 \pm 400^{b}$ & $27940 \pm 180^{c}$ \\
\hline \multirow[t]{2}{*}{4} & $\mathbf{T}$ & $2130 \pm 510^{\mathrm{c}}$ & $900 \pm 40^{\mathrm{b}}$ & $2020 \pm 210^{\mathrm{c}}$ & $3640 \pm 100^{\mathrm{c}}$ \\
\hline & $\mathbf{C}$ & $1030 \pm 380^{\mathrm{c}}$ & $4410 \pm 980^{c}$ & $1300 \pm 50^{b}$ & $5580 \pm 350^{\mathrm{c}}$ \\
\hline \multirow[t]{2}{*}{5} & $\mathbf{T}$ & No Inhibition & $230 \pm 70^{\mathrm{d}}$ & No Inhibition & $2440 \pm 760^{\mathrm{c}}$ \\
\hline & $\mathbf{C}$ & No Inhibition & $\leq 100 \pm 40^{\mathrm{d}}$ & No Inhibition & $3070 \pm 50^{c}$ \\
\hline \multirow[t]{2}{*}{6} & $\mathbf{T}$ & $870 \pm 360^{c}$ & $4340 \pm 650^{c}$ & $350 \pm 50^{d}$ & $450 \pm 40^{\mathrm{d}}$ \\
\hline & $\mathbf{C}$ & $180 \pm 70^{\mathrm{d}}$ & $10490 \pm 1460^{c}$ & $510 \pm 50^{d}$ & $450 \pm 40^{\mathrm{d}}$ \\
\hline \multirow{2}{*}{7} & $\mathbf{T}$ & $\leq 40 \pm 10^{\mathrm{d}}$ & $\leq 100 \pm 30^{\mathrm{d}}$ & $\leq 130 \pm 30^{\mathrm{d}}$ & $600 \pm 30^{\mathrm{b}}$ \\
\hline & $\mathbf{C}$ & $\leq 80 \pm 30^{\mathrm{d}}$ & $220 \pm 30^{d}$ & $170 \pm 20^{\mathrm{d}}$ & $600 \pm 100^{b}$ \\
\hline \multirow{2}{*}{8} & $\mathbf{T}$ & No Inhibition & $360 \pm 100^{\mathrm{d}}$ & No Inhibition & $\leq 60 \pm 20^{\mathrm{d}}$ \\
\hline & $\mathbf{C}$ & No Inhibition & $80 \pm 40^{\mathrm{d}}$ & No Inhibition & $\leq 80 \pm 20^{\mathrm{d}}$ \\
\hline
\end{tabular}

${ }^{\mathrm{a}} k_{\text {inact }} / K_{\mathrm{I}}$ values were taken from the published results (ref. 15 ). ${ }^{\mathrm{b}} k_{\text {inact }} / K_{\mathrm{I}}$ was determined from a linear fit of the $k_{\mathrm{obs}}$ versus [I] data. ${ }^{c} k_{\text {inact }}$ and $K_{\mathrm{I}}$ was determined from a nonlinear fit of the

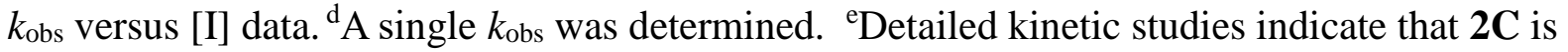
actually a reversible inhibitor of PAD2 with a $K_{\mathrm{i}}$ value of $25.2 \mu \mathrm{M}$ (see Figure S7). 


\section{SCHEME LEGENDS}

Scheme 1. Chemical structures and the synthesis of compounds 1-8.

\section{FIGURE LEGENDS}

Figure 1. (A) PAD-catalyzed citrullination of peptidyl-arginine. (B) Chemical structures of pan-PAD inhibitors and the $k_{\text {inact }} / K_{\mathrm{I}}$ values for BB-Cl-Amidine. $(\mathrm{C})$ Cocrystal structure of PAD4 bound to BB-F-Amidine indicating the covalent modification of Cys645 by the inhibitor (PDB code 5NOM). ${ }^{15}$

Figure 2. (A) The chemical structures of trans- and cis-isomers of compounds 1-8 (see Scheme 1 for variable groups). (B) The change in the UV-vis spectra of compound $\mathbf{1}$ upon irradiation with UV-A, demonstrating the photoisomerization of 1T into 1C. (C) Optimisation of UVA-exposure time from the change in absorbance of $\mathbf{1}$ at $324 \mathrm{~nm}$. (D) Photoisomerization of compound 2 monitored by UV-Vis spectra. (E) Thermal stability of $\mathbf{1 C}$ in aqueous buffer at $37{ }^{\circ} \mathrm{C}$. Assay conditions: compound $\mathbf{1}(30 \mu \mathrm{M}), 100 \mathrm{mM}$ TRIS pH 7.4, $50 \mathrm{mM} \mathrm{NaCl}$.

Figure 3. Concentration dependence of pseudo-first-order rate constant of inactivation $\left(k_{\mathrm{obs}}\right)$ of PAD2 by 1T (A) and 1C (B). (C) Potencies $\left(k_{\text {inact }} / K_{\mathrm{I}}\right)$ of trans- and $c i s$-isomers of compounds 1-8 for the inhibition of PAD2. Assay conditions: PAD2 $(2 \mu \mathrm{M}), 100 \mathrm{mM}$ TRIS pH 7.4, $50 \mathrm{mM} \mathrm{NaCl}, 2 \mathrm{mM}$ DTT, $10 \mathrm{mM} \mathrm{CaCl}_{2}$, and $10 \mathrm{mM}$ BAEE. 
Figure 4. (A) Chemical structure of RFA. (B) Workflow of labelling of PAD2 with RFA in the presence of inhibitors. RFA-labelling of PAD2 in the presence of $\mathbf{1 T}$ and $\mathbf{1 C}(\mathrm{C}), \mathbf{2 T}$ and 2C (D), 3T and 3C (E). F and C stands for fluorograph and coomassie stain, respectively. Concentrations of inhibitors [I] are given in micromolar $(\mu \mathrm{M})$. Intensities of each band in the fluorograph were measured using ImageJ software and the relative decrease in the fluorescence intensity has been plotted against the concentration of inhibitor to obtain the $\mathrm{IC}_{50}$ values. Assay conditions: PAD2 $(2 \mu \mathrm{M}), 100 \mathrm{mM}$ TRIS pH 7.4, $50 \mathrm{mM} \mathrm{NaCl}, 2 \mathrm{mM}$ DTT, and $10 \mathrm{mM} \mathrm{CaCl}_{2}$.

Figure 5. Inhibition of histone H3 citrullination in HEK293T/PAD2 cells by compound 1. Inhibitor concentrations [I] are given under each lane of the western-blot image. Citrullinated H3 (H3Cit) and H3 are shown in red and green, respectively. Quantification of each band yielded the $\mathrm{H} 3 \mathrm{Cit} / \mathrm{H} 3$ ratio, from which the $\%$ relative $\mathrm{H} 3$ citrullination was calculated. 